\title{
Thermodynamic Performance Analysis of Turbine-Bleeding Organic Rankine Cycle with and without Regeneration
}

\author{
Kyoung Hoon Kim \\ Department of Mechanical Engineering, Kumoh National Institute of Technology, Daehakro 61, \\ Gumi, Gyeongbuk 39177, Korea.
}

\begin{abstract}
This paper presents a thermodynamic performance analysis of turbine-bleeding organic Rankine cycle (ORC) with and without regeneration using internal heat exchanger based on the first and second thermodynamic laws for the recovery of low-grade finite heat source. The effects of the important system parameters including turbine bleeding pressure, turbine inlet pressure, and working fluid on the system performance were intensively investigated. Results showed that there exists an optimum turbine bleeding pressure for the maximum second-law efficiency. The system performance under the optimal condition is significantly influenced by the turbine inlet pressure, regeneration, and working fluid. The greatest exergy destruction of the system varies depending on the system parameters.
\end{abstract}

\section{Key words: Organic Rankine cycle (ORC); Turbine bleeding; Optimal condition; Energy; Exergy}

\section{INTRODUCTION}

The organic Rankine cycle (ORC) is considered as a viable technology for efficient recovery of lowtemperature heat source owing to their many advantages over conventional Rankine cycle with water as the working fluid. In recent decades, intense research has been conducted on ORC. Some of them are Dai et al. [1], Heberle and Brueggemann [2], Hung et al. [3], Tchanche et al. [4], and Kim and PerezBlanco [5], among others. Bao and Zhao [6] reported a comprehensive review of working fluid selection and the choice of expansion machines operating in the ORC system. Lecompte et al. [7] discussed the performance potential of cycle modifications to the basic ORC focused on waste heat recovery applications.

ORCs operated with turbine bleeding connected to a feed heater are typically designated as regenerative ORCs, and these are similar to the ORC with regeneration using an internal heat exchanger. Mago et al. [8] conducted an analysis of an ORC with turbine bleeding for conversion of low-temperature waste energy to power. They showed that the turbinebleeding ORC produces higher thermal efficiency and lower irreversibility then the basic ORC. Desai and
Bandyohyay [9] investigated on ORC incorporating regeneration and turbine bleeding. They proposed a methodology for appropriate integration and optimization of an ORC as a cogeneration process with the background process. Meinel et al. [10] carried out simulations of a two-stage ORC concept where the extracted vapor from the first turbine stage is used to recuperated the fluid to saturated liquid before the liquid is pressurized to the evaporation pressure with feed pump. Yekoladio et al. [11] presented a thermodynamic performance analysis of ORC using turbine bleeding for the recovery of geothermal heat sources in the range from $110^{\circ} \mathrm{C}$ to $160^{\circ} \mathrm{C}$ to maximize power output and improve the first and second law efficiencies.

This study carried out a thermodynamic performance analysis of a turbine-bleeding ORC with and without regeneration for recovery of lowtemperature heat source. The effects of the regeneration using an internal heat exchanger, working fluid and the important system parameters such as turbine bleeding pressure and turbine inlet pressure on the system performance were intensively investigated. The exergy destruction ratios at each component as well as the second-law efficiency of the system, and the 

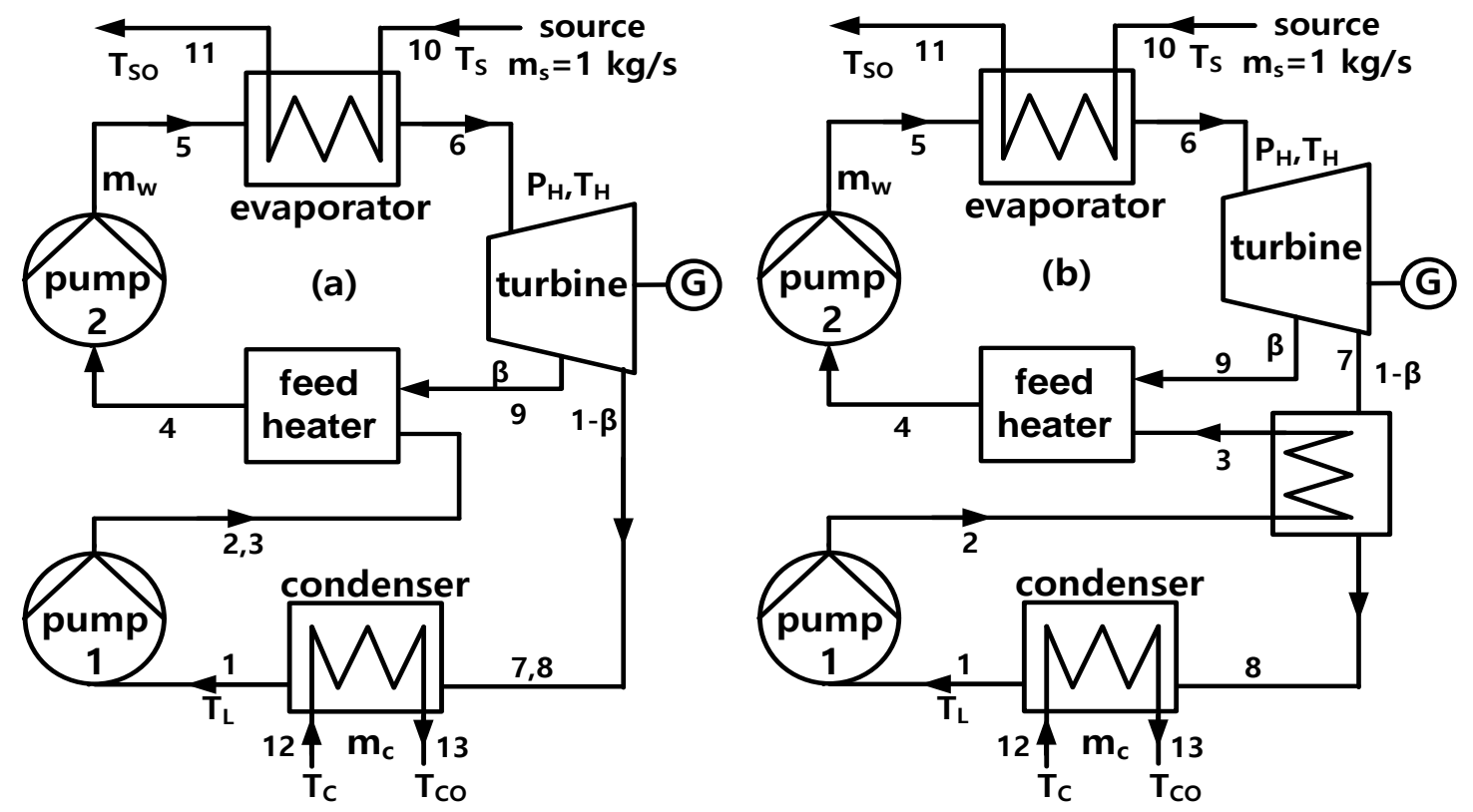

Fig 1 Schematic diagrams of cycles without (a) and with regeneration (b).

optimal performance for the maximum second-law efficiency were also comparatively investigated.

\section{SYSTEM ANALYSIS}

This study comparatively evaluated the thermodynamic performances of the turbine-bleeding ORC without regeneration (called as basic cycle) and with regeneration (called as regeneration cycle) whose schematic diagrams are shown in Fig. 1 (a) and 1 (b), respectively. In the regeneration cycle, the working fluid exits the condenser as a saturated liquid at temperature $\mathrm{T}_{\mathrm{L}}$ (state 1). The fluid enters pump 1 and is pressurized to the turbine bleeding pressure $\mathrm{P}_{\mathrm{B}}$ (state 2). The fluid is then heated in the regenerator (state 3) while the working fluid out of the turbine (state 7) is cooled (state 8 ). The fluid is then heated in the feed heater (state 4) by mixing with the working fluid extracted from the turbine (state 9). The fluid is then compressed again in pump 2 to the turbine inlet pressure (state 5). The working fluid is evaporated with the finite heat source and leaves the evaporator as a saturated vapor at temperature $\mathrm{T}_{\mathrm{H}}$ (state 6 ). The source fluid enters the evaporator at $T_{S}$ (state 10) and leaves at $\mathrm{T}_{\mathrm{SO}}$ (state 11) after heating the working fluid in the evaporator. The coolant is supplied at temperature $\mathrm{T}_{\mathrm{C}}$ (State 12) and exits the condenser at temperature $\mathrm{T}_{\mathrm{CO}}$ (State 13).

For the simulation some assumptions are made as follows [12]: The isentropic efficiencies of the pumps and turbine are constant. The cycle is subcritical, so the turbine inlet pressure is lower than the critical pressure of the working fluid. The working fluid leaves the feed heater as a saturated liquid. Each of the heat exchangers is operated with a pinch-point condition, which means the maximum flow rate of the working fluid in the evaporator for a given source fluid and the minimum flow rate of the coolant in the condenser for a given working fluid.

For a given mass flow rate of the source fluid ms, the mass flow rates of the working fluid $\mathrm{mw}$, and the coolant $\mathrm{mc}$ are obtained as follows:

$$
\begin{gathered}
m_{w}=\frac{m_{s} c_{s}\left(T_{10}-T_{11}\right)}{h_{6}-h_{5}} \\
m_{c}=\frac{m_{w}(1-\beta)\left(h_{8}-h_{1}\right)}{c_{c}\left(T_{13}-T_{12}\right)}
\end{gathered}
$$

The bleeding ratio $\beta$ can be determined from the condition that the fluid leaves the feed heater as a saturated liquid.

$$
\beta=\frac{h_{4}-h_{3}}{h_{9}-h_{3}}
$$

The heat addition rate $\mathrm{Q}_{\text {in }}$, the turbine power production $\mathrm{W}_{\mathrm{t}}$, the pump power $\mathrm{W}_{\mathrm{p}}$, and the net power production $\mathrm{W}_{\text {net }}$, are determined as follows:

$$
\begin{gathered}
Q_{i n}=m_{s} c_{s}\left(T_{10}-T_{11}\right)=m_{w}\left(h_{6}-h_{5}\right) \\
W_{t}=m_{w} \beta\left(h_{6}-h_{9}\right)+m_{w}(1-\beta)\left(h_{6}-h_{7}\right) \\
W_{p}=m_{w}(1-\beta)\left(h_{2}-h_{1}\right)+m_{w}\left(h_{5}-h_{4}\right) \\
W_{n e t}=W_{t}-W_{p}
\end{gathered}
$$

Exergy destruction is the measure of irreversibility of a process and an exergy analysis identifies the location, the magnitude, and the source of thermodynamic inefficiencies, and can be the basis of an 
economic analysis of a thermal system [13-14]. The exergy is defined as:

$$
E=m\left[h-h_{0}-T_{0}\left(s-s_{0}\right)\right]
$$

Here the subscript 0 denotes the dead state. The exergy input to the system by the source fluid, $\mathrm{E}_{\mathrm{in}}=\mathrm{E}_{10}$, should be equal to the sum of the net power production and the total exergy destruction including exergy losses $\mathrm{d}_{\mathrm{tot}}$.

$$
E_{\text {in }}=W_{\text {net }}+d_{\text {tot }}
$$

The thermal efficiency $\eta_{\text {th }}$, second-law efficiency $\eta_{\mathrm{II}}$, and exergy efficiency $\eta_{\mathrm{ex}}$, are defined as the ratio of the net power production to the total energy input, net exergy input and source exergy input, respectively.

$$
\begin{gathered}
\eta_{t h}=W_{\text {net }} / Q_{\text {in }} \\
\eta_{I I}=W_{\text {net }} /\left(E_{10}-E_{11}\right) \\
\eta_{e x}=W_{\text {net }} / E_{s}
\end{gathered}
$$

The parameter $\mathrm{D}$ is defined as the ratio of the exergy destruction of a component to the exergy input. The sum of the exergy destruction ratios of the system and the exergy efficiency then becomes unified [12].

$$
\eta_{e x}+D_{s o}+D_{c o}+D_{h}+D_{r}+D_{c}+D_{m}+D_{t p}=1
$$

where $\mathrm{D}_{\mathrm{so}}$ is the exergy loss ratio of the source exhaust, and $D_{c o}, D_{h}, D_{r}, D_{c}, D_{m}$, and $D_{t p}$ are the exergy destruction ratios of the coolant exhaust, evaporator, regenerator, condenser, feed heater, and turbine/pump, respectively. The mathematical expressions of the exergy destruction ratios are listed in Table 1.

Table 1 Mathematical expressions of the exergy destruction ratios.

The working fluid plays a key role in the cycle and by considering the condensing property at low temperatures and thermal stability at high temperatures, four fluids, isobutane, R245fa, R123, and isopentane,

\begin{tabular}{ccc}
\hline Symbol & Component & Expression \\
\hline$D_{h}$ & Evaporator & $\left(E_{5}+E_{10}-E_{6}-E_{11}\right) / E_{\text {in }}$ \\
$D_{r}$ & Regenerator & $\left(E_{2}+E_{7}-E_{3}-E_{8}\right) / E_{\text {in }}$ \\
$D_{c}$ & Condenser & $\left(E_{8}+E_{12}-E_{1}-E_{13}\right) / E_{\text {in }}$ \\
$D_{m}$ & Feed heater & $\left(E_{3}+E_{9}-E_{4}\right) / E_{\text {in }}$ \\
$D_{t p}$ & Turbine/pump & $\left(E_{1}+E_{6}-E_{2}-E_{7}-E_{9}\right) / E_{\text {in }}$ \\
$D_{c o}$ & Coolant exhaust & $E_{11} / E_{\text {in }}$ \\
$D_{s o}$ & Source exhaust & $E_{13} / E_{\text {in }}$ \\
\hline
\end{tabular}

were selected. In this study, the thermodynamic properties of the working fluids were evaluated by the Patel-Teja equation of state [15-16] using MathCAD programming. The basic data of the fluids are shown in Table 2, where $\mathrm{M}, \mathrm{T}_{\mathrm{cr}}, \mathrm{P}_{\mathrm{cr}}$, and $\omega$ are the molecular weight, critical temperature, critical pressure, and acentric factor, respectively [17].
Table 2 Basic thermodynamic data of working fluids.

\section{RESULT AND DISCUSSION}

In this study, the source fluid is water with $1 \mathrm{~kg} / \mathrm{s}$. The input values used as the base case for the cycle simulation are listed in Table 3.

\begin{tabular}{ccccc}
\hline Substance & $M(\mathrm{~kg} / \mathrm{kmol})$ & $T_{\text {cr }}(\mathrm{K})$ & $P_{\text {cr }}(\mathrm{bar})$ & $\omega$ \\
\hline isobutane & 58.123 & 408.14 & 36.48 & 0.177 \\
R245fa & 134.048 & 427.20 & 36.40 & 0.3724 \\
R123 & 136.467 & 456.90 & 36.74 & 0.282 \\
isopentane & 72.150 & 460.43 & 33.81 & 0.228 \\
\hline
\end{tabular}

Table 3 Basic simulation conditions of the system.

\begin{tabular}{cccc}
\hline symbol & description & value & unit \\
\hline$m_{s}$ & mass flow rate of source fluid & 1 & $\mathrm{~kg} / \mathrm{s}$ \\
$T_{s}$ & source temperature & 200 & ${ }^{\circ} \mathrm{C}$ \\
$T_{H}$ & turbine inlet temperature & 190 & ${ }^{\circ} \mathrm{C}$ \\
$p_{H}$ & reduced turbine inlet pressure & 0.8 & \\
$T_{L}$ & condensation temperature & 30 & ${ }^{\circ} \mathrm{C}$ \\
$T_{c}$ & coolant temperature & 15 & ${ }^{\circ} \mathrm{C}$ \\
$\Delta T_{p p}$ & pinch temperature difference & 8 & ${ }^{\circ} \mathrm{C}$ \\
$T_{0}$ & dead state temperature & 8 & ${ }^{\circ} \mathrm{C}$ \\
$P_{0}$ & dead state pressure & 1 & atm \\
$\eta_{p}$ & isentropic efficiency of pump & 80 & $\%$ \\
$\eta_{t}$ & isentropic efficiency of turbine & 80 & $\%$ \\
\hline
\end{tabular}

Here the reduced pressure is defined as the ratio the pressure to the critical pressure of the working fluid.

Fig. 2 displays the effects of the reduced bleeding pressure $\mathrm{p}_{\mathrm{B}}$, on the bleeding ratio $\beta$ for the various working fluids. In the figure the solid and open symbols represent the basic and regeneration cycles, respectively. The figure shows that the bleeding ratio increases with increasing turbine bleeding pressure. This is because the bleeding ratio increases with increasing enthalpy at the feed heater exit $h_{4}$, and decreases with increasing enthalpy of bleeding flow, $\mathrm{h}_{9}$. As the bleeding pressure increases, both the enthalpies of $h_{4}$ and $h_{9}$ increase; however, the bleeding ratio increases because the increase in $\mathrm{h}_{4}$ is greater than the increase in ${ }_{\mathrm{h}}$. For a specified working fluid, the bleeding ratio in regeneration cycle is lower than the basic cycle. It is because as the bleeding ratio decreases with increasing $h_{3}$, the enthalpy of the working fluid entering the feed heater, which can be seen from Eq. (3). In addition, $h_{3}$ in regeneration cycle is higher than that in basic cycle. As shown in the figures, there is a lower limit for the bleeding ratio, where the bleeding ratio is 


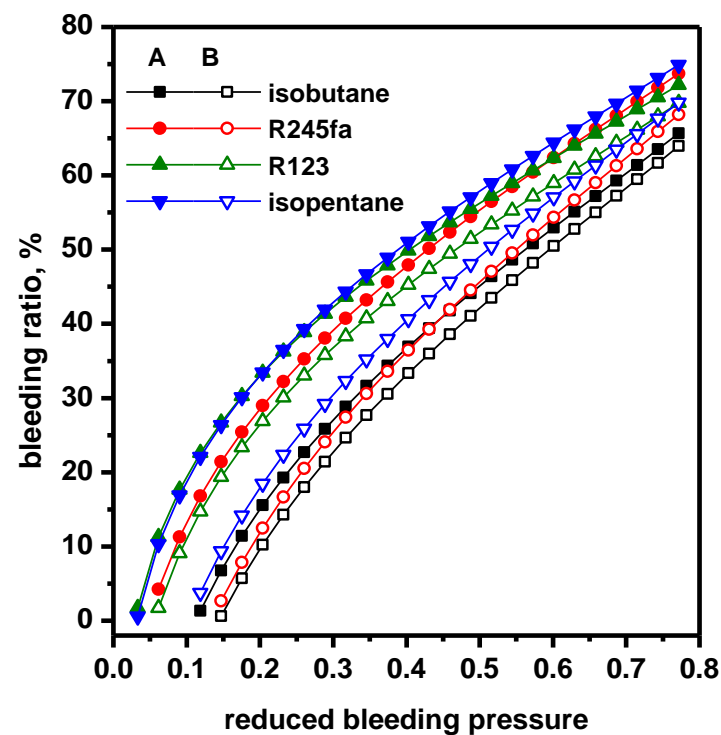

Fig 2 Effects of bleeding pressure on the bleeding ratio for various working fluids.

reduced to zero. This implies that it is impossible to make the working fluid a saturated liquid at the feed heater exit when the bleeding ratio is lower than the lower limit.

Fig. 3 shows the effects of the bleeding pressure on the net power production. The net power production decreases with increasing bleeding pressure, because as the bleeding pressure increases, the bleeding ratio increases, which leads to a decreased mass flow rate of the working fluid at the turbine and reduced turbine power production. For a specified working fluid, the net power production in regeneration cycle is higher than basic cycle. It is because the bleeding ratio in

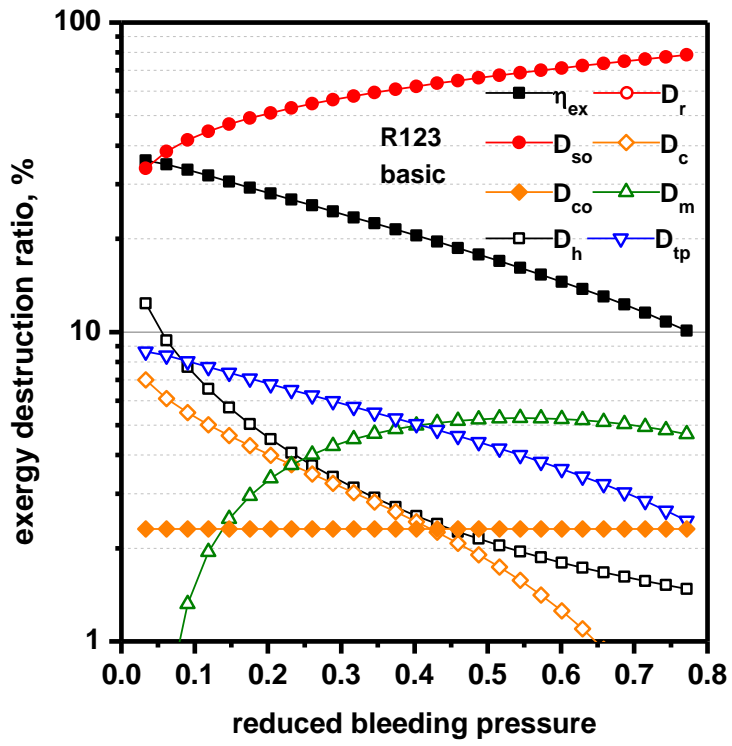

Fig 6 Effects of bleeding pressure on the exergy destruction ratios in the basic cycle.

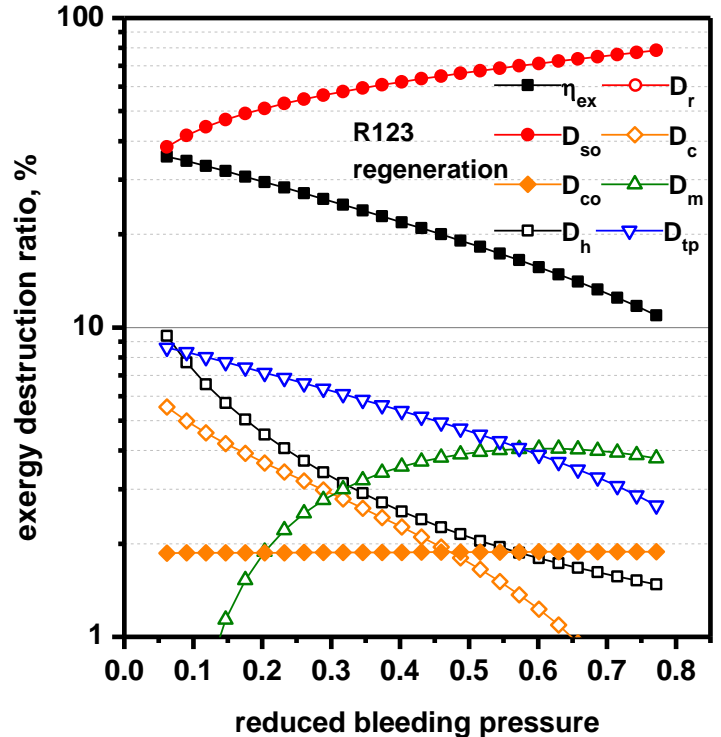

Fig 7 Effects of bleeding pressure on the exergy destruction ratios in the regeneration cycle.

regeneration cycle is lower than basic cycle, which leads to an increased mass flow rate and, consequently, an increased power production at the turbine. The net power production increases with decreasing critical temperature of the working fluid; therefore, so the net power production is the highest for isobutane and the lowest for isopentane.

Figs. 4 and 5 show the effects of bleeding pressure on the thermal and second-law efficiencies, respectively. Each of the thermal and second-law efficiencies contains a peak value with respect to the bleeding pressure. This is because both the heat input rate from the source fluid and the net power production decrease with increasing bleeding pressure. For a specified working fluid, the thermal and second-law efficiencies in regeneration cycle are higher than the basic cycle, since the net power production in regeneration cycle is higher than the basic cycle, while the heat input rate in regeneration cycle is the same as the basic cycle. For a specified reduced bleeding pressure, the order of working fluid for high thermal efficiency varies depending on the turbine inlet condition or regeneration.

Exergy analysis allows exergy destructions to be identified and graded by importance, and this knowledge would be useful to draw attention to aspects of system performance that provide the opportunities for improvement through the application of practical engineering. The component where the exergy destruction ratio is great suggests that it would be important to reduce the exergy destruction to improve system performance [18]. Figs. 6 and 7 show the effects of the bleeding pressure on the exergy destruction ratios in basic and regeneration cycles, when the working fluid 


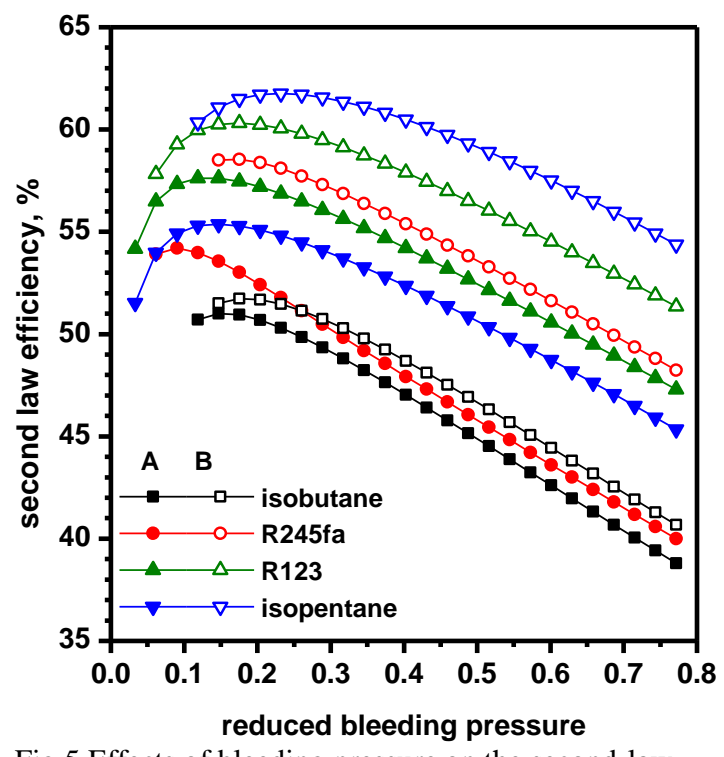

Fig 5 Effects of bleeding pressure on the second-law efficiency for various working fluids.

This study presented an exergy analysis of a turbine-bleeding ORC with and without regeneration for recovery of low-grade heat sources. The effects of the turbine bleeding pressure, turbine inlet pressure, working fluid, and regeneration on the system performance were theoretically investigated. Water at $200{ }^{\circ} \mathrm{C}$ with $1 \mathrm{~kg} / \mathrm{s}$ was considered as the heat source, and the four fluids of isobutane, R245fa, R123, and isopentane were considered as the working fluids.

The results showed that the net power production of the system decreases with increasing bleeding pressure; however, the thermal and second-law efficiencies exhibit a peak with respect to the bleeding pressure. The exergy, thermal, and second-law efficiencies in regeneration cycle are higher than those in basic cycle. The order of working fluid for high thermal or second-law efficiency and the greatest exergy destruction ratio varies depending on the turbine inlet condition or regeneration.

The working fluid producing the highest secondlaw efficiency is R123 in the basic cycle, while isopentane in the regeneration cycle. The exergy destruction ratio of source exhaust is the highest among all of the exergy loss or destruction ratios over the entire range of the simulated conditions, while the second greatest one varies depending on the turbine inlet condition or regeneration.

\section{ACKNOWLEDGMENTS}

This research was supported by Basic Science Research Program through the National Research Foundation of Korea (NRF) funded by the Ministry of Education, Science and Technology (No. 2016935888). is $R 123$. The ratio of source exhaust $\left(D_{s o}\right)$ increases with the bleeding pressure. However, the ratio of the coolant exhaust $\left(\mathrm{D}_{\mathrm{co}}\right)$ remains almost constant, and the ratio of the feed heater $\left(D_{m}\right)$ has a peak with respect to the bleeding pressure. The other ratios decrease as the bleeding pressure increases. The ratio of the source exhaust $\left(D_{\text {so }}\right)$ is the biggest among the ratios of the system. It can be seen from the figure that the second biggest ratio besides the ratio of source exhaust varies depending on the bleeding pressure; It becomes the ratio of evaporator for low bleeding pressures, the ratio of turbine and pump $\left(\mathrm{D}_{\mathrm{tp}}\right)$ for middle bleeding pressures, and the ratio of feed heater $\left(\mathrm{D}_{\mathrm{m}}\right)$ for high bleeding pressure; therefore, it varies depending on the bleeding pressure.

\section{CONCLUSION}

\section{REFERENCES}

[1] Dai, Y., Wang, J., and Gao, L., 2009, "Parametric optimization and comparative study of organic Rankine cycle (ORC) for low grade waste heat recovery, "Energy Convers. Manag. Vol. 50, pp. 576-582.

[2] Heberle, F. and Brueggemann, D., 2010, "Exergy based fluid selection for a geothermal organic Rankine cycle for combined heat and power generation," Appl. Therm. Eng. Vol. 30, pp. 13261332.

[3] Hung, T.C., Wang, S.K., Kuo, C.H., Pei, B.S., and Tsai, K.F., 2010, "A study of organic working fluids on system efficiency of an ORC using lowgrade energy sources," Energy, Vol. 35, pp. 14031411.

[4] Tchanche, B.F., Pétrissans, M., and Papadakis, G., 2014, "Heat resources and organic Rankine cycle machines," Renew. Sustain. Energy Rev. Vol. 39, pp. 1185-1199.

[5] Kim, K.H. and Perez-Blanco, H., 2015, "Performance Analysis of a Combined Organic Rankine Cycle and Vapor Compression Cycle for Power and Refrigeration Cogeneration," Appl. Therm. Eng., Vol. 91, pp. 964-974.

[6] Bao, J. and Zhao, L. A., 2013, "Review of working fluid and expander selections for organic Rankine cycle," Renew. Sustain. Energy Rev., Vol. 24, pp. 325-342.

[7] Lecompte, S., Huisseune, H., van den Broek, M., Vanslambrouck, B., and De Paepe, M., 2015, "Review of organic Rankine cycle (ORC) architectures for waste heat recovery," Renew. Sustain. Energy Rev., Vol. 47, pp. 448-461.

[8] Mago, P.J., Chamra, L.M., Srinivasan, K., and Somayaji, C., 2008, "An examination of 
Kyoung Hoon Kim/ Journal of Engineering and Science Research, 2 (1) 2018, Pages: 23-28

regenerative organic Rankine cycles using dry fluids," Appl. Therm. Eng., Vol. 28, pp. 998-1007.

[9] Desai, N.B. and Bandyopadhyay, S., 2009, "Process integration of organic Rankine cycle," Energy, Vol. 34, pp. 1674-1686.

[10] Meinel, D., Wieland, C. and Spliethoff, H., 2014, "Effect and comparison of different working fluids on a two-stage organic rankine cycle (ORC) concept," Appl. Therm. Eng., Vol. 63, pp. 246253.

[11] Yekoladio, P.J., Bello-Ochende, T., and Meyer, J.P., 2015, "Thermodynamic analysis and performance optimization of organic rankine cycles for the conversion of low to moderate grade geothermal heat," Int. J. Energy Res., Vol. 39, pp. 1256-1271.

[12] Lee H.Y. and Kim K.H., 2015, "Energy and Exergy Analyses of a Combined Power Cycle Using the Organic Rankine Cycle and the Cold Energy of Liquefied Natural Gas," Entropy, Vol. 17, pp. 6412-6432.

[13] Bejan, A., 2006, "Advanced Engineering Thermodynamics," 3rd ed., John Wiley \& Sons, New York, NY, USA.
[14] Kim K.H. and Kim K., 2015, "Comparative Analyses of Energy-Exergy-Entransy for the Optimization of Heat-Work Conversion in Power Generation Systems," Int. J. Heat Mass Transfer, Vol. 84, pp. 80-90.

[15] Yang, T., Chen, G.J., and Guo, T.M., 1997, "Extension of the Wong-Sandler mixing rule to the three-parameter Patel-Teja equation of state: Application up to the near-critical region," Chem. Eng. J., Vol. 67, pp. 27-36.

[16] Gao, J., Li, L.D., Zhu, Z.Y., and Ru, S.G., 2004, "Vapor-liquid equilibria calculation for asymmetric systems using Patel-Teja equation of state with a new mixing rule," Fluid Phase Equilibria, Vol. 224, pp. 213-219.

[17] Yaws, C.L., 1999, "Chemical Properties Handbook," McGraw-Hill, New York, NY, USA.

[18] Moran, M.J., and Shapiro H.N., 2006, "Fundamentals of Engineering Thermodynamics," 5th Ed., John Wiley \& Sons, Chichester, West Sussex, England. 